\title{
Optimization of Plastic Moulding by Reducing Warpage With the Application of Taguchi Optimization Technique \& Addition of Ribs in Washing Machine Wash Lid Component
}

\author{
Pranav Sanap*, H M Dharmadhikari, A J Keche \\ Department of Mechanical Engineering, MIT, Aurangabad, India
}

\begin{abstract}
This paper deals with the optimization of plastic moulding by reducing warpage with the application of Taguchi optimization technique \& part design modifications. Taguchi optimization technique is used for determining the optimum plastic injection moulding process parameters. In part design modifications, ribs are added to the wash lid component to provide additional strength to the washing machine. Analysis of the process parameters are initially carried out by utilizing the combination of process parameters based on three-level of L27 Taguchi orthogonal design. Further, signal-to-noise $(S / N)$ ratio is applied to find the optimum process parameters for warpage defect in the wash lid component. The design modifications and analysis for warpage using optimum parameters obtained from S/N ratio using Pro-E design software and Solid Edge Plastic analysis software. The results obtained reveals that improvement in total warpage is $22.0 \%$ \& in X-direction it is $37 \%$ and stress distribution is by $28 \%$ which proves that the strength of the wash lid has increased.
\end{abstract}

Keywords: Ribs, Taguchi Optimization technique, Warpage

\section{Introduction}

Plastic injection moulding is one of the most important method applied for plastic products in home appliances industry. Plastic injection molding (PIM) has also some advantages such as short product cycles, high quality part surfaces, good mechanical properties, low cost, and light weight, so it is becoming increasingly more significant in today's plastic production industries. The process of PIM can be summarized shortly: the polymer material is heated to its melting temperature. The melted polymer is injected into the cavity by a gate under high pressure, below the freezing temperature of the polymer. When filling is nearly completed, the cavity is kept at a constant pressure for the packing pressure. Packing pressure is utilized to fill the remaining volume of the cavity and to reduce the shrinkage due to cooling. If cools down, the shrinkage occurs in the cavity. When the inner of the cavity is stable case, the plastic product is extracted from the mold $[1,4]$

The quality of the plastic injection parts depends on the materials, the parts and mold design, and the parameters of the manufacturing process. Shrinkage and warpage are two common defects in the injection molding process. The shape of the micro injected part is the primary cause of warpage. Other possible causes of warpage are non-uniform wall thicknesses, non-uniform packing pressures in the mold cavities, and nonuniform molding temperatures or cooling rates. The molecular structure of the material (amorphous, crystalline) is also important in reducing warpage. Warpage is also caused by the non-uniformity of the shrinkage because of the residual stresses induced by the complex thermal variations

inside the mold. In injection molding, designing an ideal cooling system is sometimes impossible because the position of the cooling circuit depends heavily on the part's geometry, its cavity configuration, and the location of the ejection mechanism. Therefore, a variation in the temperature across the injected part is expected, depending on the geometry [1].

\section{Literature Review}

Hakimian \& Sulong studied the warpage for microgears containing four cavities and consisting of three different types of thermoplastic materials, namely, the amorphous polycarbonate/ acrylonitrile-butadienestyrene blend (PC/ABS), amorphous polyphenylene-ether/polystyrene (PPE/PS), and crystalline polyoxymethylene (POM) filled with glass fibers were analyzed. Molding parameters such as packing time, cooling temperature, molding and melting temperatures, packing and injection pressures, and fiberglass percentages are the most important factors affecting warpage and shrinkage. Three factors and their interactions were investigated in this case study. The effects of the injection parameters on warpage and shrinkage at different fiberglass percentages and cooling temperatures were analyzed according to the Taguchi method. The minimum values for warpage $(0.0051 \mathrm{~mm})$ and shrinkage $(2.2886 \%)$ were derived from the PC/ABS and PPE/PS composites [2]

Nik Mizamzul Mehata, Shahrul Kamaruddin used the Taguchi method for the optimization to improve the mechanical properties of products made from recycled plastic. The results revealed that the product made of 
$25 \%$ recycled polypropylene (PP) and $75 \%$ virgin PP exhibits a better flexural modulus compared to the virgin form. The same product exhibits a 3.4\% decrease in flexural strength. The degradation in mechanical properties of products produced from recycled plastic can be improved by optimizing the influence processing parameters during the manufacturing process. [3]

Ming-Chih Huang, Ching-Chih Tai studied the effect of various parameters on the warpage \& the results showed that the packing pressure had the greatest influence on the warpage, followed by mold temperature, melt temperature, and packing time. However, the warpage was only slightly influenced by the gate dimension and the filling time in thin shell injection molding the packing pressure is the most influential factor, which shows a contribution rate of $15.59 \%$. The second is the mold temperature at $12.14 \%$, followed by the melt temperature at $10.76 \%$, and the packing time at $9.61 \%$. 1) The range of packing pressure was set from 40 to $100 \%$ of the injection pressure, when the packing pressure was higher than $85 \%$ of the injection pressure, the warpage was obviously increasing. 2) The range of mold temperature was set from 40 to $1058 \mathrm{C}$. The ideal mold temperature range was from 85 to $958 \mathrm{C}$. 3) The range of melt temperature was set from 230 to $3508 \mathrm{C}$. The warpage values at different melt temperatures are shown in Table 10. The warpage was larger between 245 and 2808C. Although the warpage was very small when the melt temperature was 2308C [4]

E. Bociga, T. Jaruga, K. Lubczyñska Studied the analysis of 'Differences in mould temperature can lead to the problems with manufactured parts like warpage'. The reason of this are stresses in the parts, Since polymer with higher temperature exhibits more intensive shrinkage than in lower temperature, the temperature differences created during part cooling in the mould lead to part distortion, due to difference in shrinkage a bending moment occurs in the part and causes deformation. Part becomes concave from the mould "hot" side and convex from the mould "cold" side. Study was made at two different conditions in which two surfaces were maintained at 20-90deg temperature \& vice versa. Similarly concave \& convex result was found. When both the mold surface temperature was maintained at 50deg, very minimum warpage was found, of about $0.25 \mathrm{~mm}$ [5]

S.Selvaraj, P.Venkataramaiah have given the method for the measurement of warpage of injection moulded plastic components using image processing. The images of components are captured by using high resolution digital camera which is fixed in the fixture. The high resolution captured images of FR lever, are processed using MATLAB-Image Processing Tool and warpage is measured by comparing with image of standard component.[6]

Sen-Yeu Yang, Shin-Chang Jiang, and Wen-Shu Lu studied the warpage in the part with plane surface $\&$ the ribbed surface. The thermal warpage during reflow condition in ribbed packages (especially the package with the border rib) can be significantly reduced if the thickness and width of the rib are appropriately selected [7]

S. Kamaruddin, Zahid A. Khan and S. H. Foong used the product (plastic tray) made from blends plastic (75\% polypropylene (PP) and $25 \%$ low density polyethylene (LDPE)) for optimizing the injection molding parameters using the Taguchi method. The analysis of the results shows that the optimal combination for low shrinkage are low melting temperature, high injection pressure, low holding pressure, long holding time and long cooling time. Using Taguchi method for design of experiment (DOE), other significant effects such as interaction among injection molding parameters are also investigated [9]

S.M. Nasir, K.A. Ismail, Z. Shayfull, M.A. Md. Derus identified the best setting for single and double gate, which affect the warpage for thick component using Taguchi and ANOVA methods. Mold Temperature, Melt Temperature, Packing Pressure and Packing Time are the selected parameter that used in this study. These experiments were performed by Autodesk Moldflow Insight (AMI) software based on L9 orthogonal array designed by Taguchi. Effects of single and double gates to the warpage formation also were compared. The results show that Taguchi method is capable to minimize the warpage deflection. moreover, double gate design was better than single gate in minimizing the warpage deflection. [10]

Gwebu, L. Nyanga, S.T. Nyadongo, A.F.Van der Merwe, S Mhlanga used Taguchi method to determine the optimum values of the injection moulding process parameters for high density polyethylene (HDPE.) plastic parts. A moulding processing window in which the process achieved maximum quality, with major focus being on mould filling is developed. [11]

From the above literature review, it is reviewed that parameters like Melting Temperature, Injection Pressure, Packaging Pressure, Packing Time, Cooling time have been studied for the warpage. But Injection Speed hasn't been studied which can be the affecting parameter for the warpage.

Warpage defect was studied either by optimization of process parameters or by part design modifications. Effect of combination of both the remedies hasn't been done.

\section{Methodology}

This project implemented on optimization of plastic injection molding process parameters by using Taguchi method. It's an effective method attempted to test a small fraction of all possible combinations by using orthogonal arrays and comes out with the solution. Therefore, it required shorter time to obtain the optimal 
parameter setting in injection moulding. Experimentation was performed as per the L27 orthogonal array of Taguchi method. Finally, MINITAB used to find out the optimal injection moulding process parameters.

Part design modifications were done in the Pro-E design software. Ribs were added to the part to give more rigidity. Modified design analyzed for the warpage in the solid edge plastic analysis software with optimal process parameters as an input. Old \& new data were compared \& the improvement in the warpage problem was calculated.

\section{Experimental set-up}

The experiments were performed using Polypropylene as raw material. For the experimental setup considered the Melting Temperature, Injection Pressure, Packaging Pressure, Packing Time, Cooling time and Injection Speed process parameters those are mostly affect on warpage.

The technical details of the injection molding machine on which project work carried out are closing force (200 ton), maximum injection pressure (180 bar),

screw pressure time $(0.02 \mathrm{~s})$, and shot size $(0.02 \mathrm{~kg})$, respectively. A large number of process variable affect the quality of products made by injection molding process.

Keeping in view the importance of the main process parameters and their effect on the performance characteristics, working range of the each parameter was carefully chosen to produce the plastic lid of acceptable quality. Each parameter level was then selected carefully with the help of study of previous researches \& on the basis experience and then experiments were performed as per the Taguchi L27 orthogonal array. Each parameter at levels 3 was considered. Table 1 shows the injection molding parameters and levels.

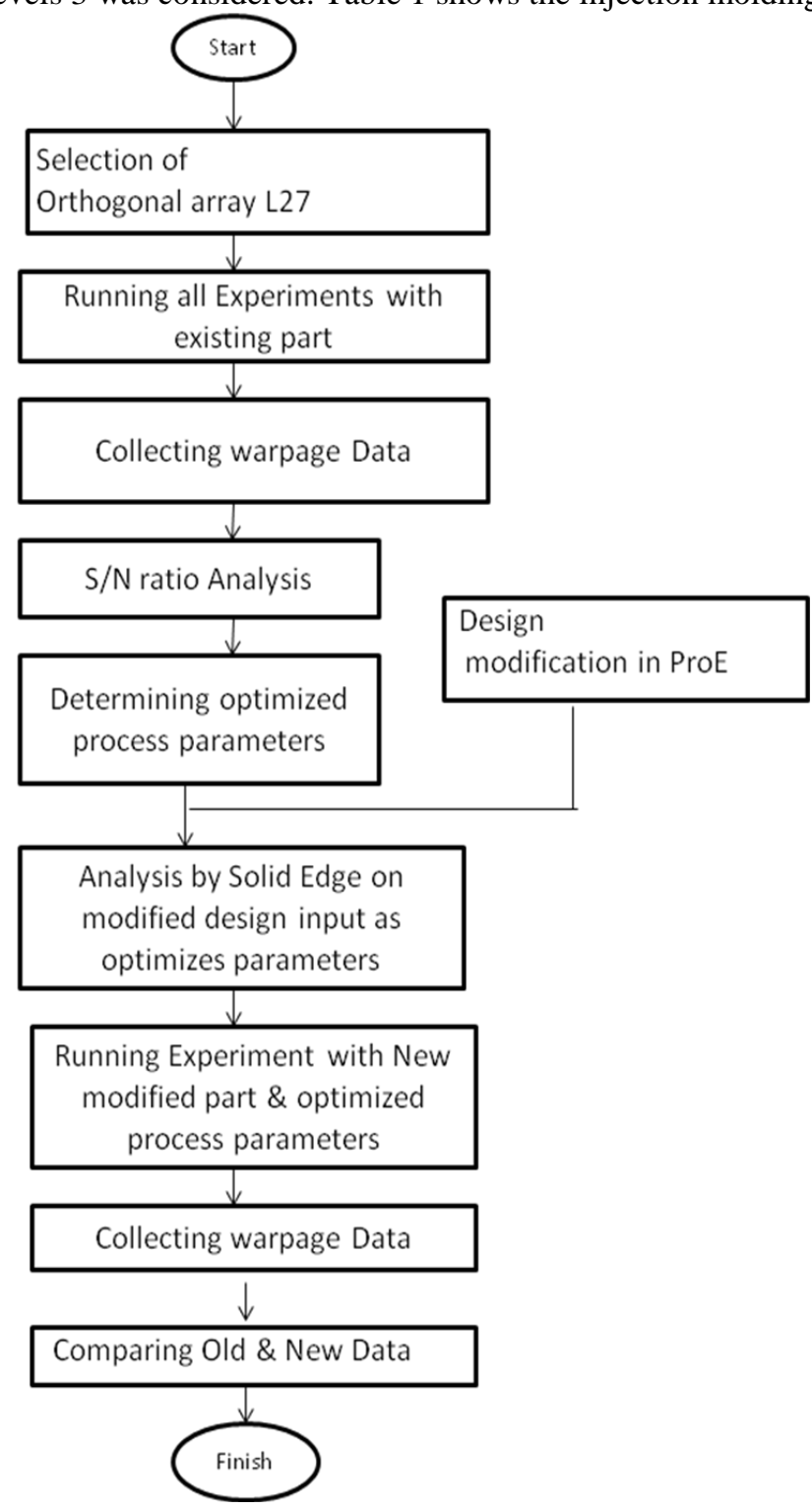

Fig 1 Experimental Flow Chart 
Optimization of plastic moulding by reducing warpage with the Application of Taguchi optimization..

\section{Selection of Orthogonal Array (OA)}

Orthogonal array L27 ( 313 ) with 13 columns and 27 rows was selected and the experiments were performed. Table 2 shows the L27 Orthogonal Array (OA) with the process parameters and their levels.

Table 1 Injection moulding parameters and their levels

\begin{tabular}{|c|c|c|c|c|c|c|c|}
\hline \multirow[t]{2}{*}{ Sr. No. } & \multirow[t]{2}{*}{ Levels } & \multicolumn{6}{|c|}{ Process Parameters } \\
\hline & & $\begin{array}{l}\text { Melting Temp. } \\
\left({ }^{0} \mathrm{C}\right) \\
\text { (A) }\end{array}$ & $\begin{array}{l}\text { Injection } \\
\text { Pressure (bar) } \\
\text { (B) }\end{array}$ & $\begin{array}{l}\text { Packing Pressure } \\
\text { (bar) } \\
\text { (C) }\end{array}$ & $\begin{array}{l}\text { Packing Time } \\
\text { (Sec) } \\
\text { (D) }\end{array}$ & $\begin{array}{l}\text { Cooling } \\
\text { Time } \\
(\mathrm{Sec})(\mathrm{E})\end{array}$ & $\begin{array}{l}\text { Injection Speed } \\
(\mathrm{mm} / \mathrm{s}) \\
(\mathrm{F})\end{array}$ \\
\hline 1 & Level 1 & 280 & 40 & 70 & 5 & 20 & 25 \\
\hline 2 & Level 2 & 290 & 50 & 80 & 10 & 25 & 30 \\
\hline 3 & Level 3 & 300 & 60 & 90 & 15 & 30 & 35 \\
\hline
\end{tabular}

Table 2 Orthogonal array L27 ( 313) used in this work

\begin{tabular}{|c|c|c|c|c|c|c|c|c|c|c|c|c|c|}
\hline \multirow[t]{2}{*}{ Experiment No. } & \multicolumn{13}{|c|}{ Column(process parameters) } \\
\hline & 1 & 2 & 3 & 4 & 5 & 6 & 7 & 8 & 9 & 10 & 11 & 12 & 13 \\
\hline 1 & 1 & 1 & 1 & 1 & 1 & 1 & 1 & 1 & 1 & 1 & 1 & 1 & 1 \\
\hline 2 & 1 & 1 & 1 & 1 & 2 & 2 & 2 & 2 & 2 & 2 & 2 & 2 & 2 \\
\hline 3 & 1 & 1 & 1 & 1 & 3 & 3 & 3 & 3 & 3 & 3 & 3 & 3 & 3 \\
\hline 4 & 1 & 2 & 2 & 2 & 1 & 1 & 1 & 2 & 2 & 2 & 3 & 3 & 3 \\
\hline 5 & 1 & 2 & 2 & 2 & 2 & 2 & 2 & 3 & 3 & 3 & 1 & 1 & 1 \\
\hline 6 & 1 & 2 & 2 & 2 & 3 & 3 & 3 & 1 & 1 & 1 & 2 & 2 & 2 \\
\hline 7 & 1 & 3 & 3 & 3 & 1 & 1 & 1 & 3 & 3 & 3 & 2 & 2 & 2 \\
\hline 8 & 1 & 3 & 3 & 3 & 2 & 2 & 2 & 1 & 1 & 1 & 3 & 3 & 3 \\
\hline 9 & 1 & 3 & 3 & 3 & 3 & 3 & 3 & 2 & 2 & 2 & 1 & 1 & 1 \\
\hline 10 & 2 & 1 & 2 & 3 & 1 & 2 & 3 & 1 & 2 & 3 & 1 & 2 & 3 \\
\hline 11 & 2 & 1 & 2 & 3 & 2 & 3 & 1 & 2 & 3 & 1 & 2 & 3 & 1 \\
\hline 12 & 2 & 1 & 2 & 3 & 3 & 1 & 2 & 3 & 1 & 2 & 3 & 1 & 2 \\
\hline 13 & 2 & 2 & 3 & 1 & 1 & 2 & 3 & 2 & 3 & 1 & 3 & 1 & 2 \\
\hline 14 & 2 & 2 & 3 & 1 & 2 & 3 & 1 & 3 & 1 & 2 & 1 & 2 & 3 \\
\hline 15 & 2 & 2 & 3 & 1 & 3 & 1 & 2 & 1 & 2 & 3 & 2 & 3 & 1 \\
\hline 16 & 2 & 3 & 1 & 2 & 1 & 2 & 3 & 3 & 1 & 2 & 2 & 3 & 1 \\
\hline 17 & 2 & 3 & 1 & 2 & 2 & 3 & 1 & 1 & 2 & 3 & 3 & 1 & 2 \\
\hline 18 & 2 & 3 & 1 & 2 & 3 & 1 & 2 & 2 & 3 & 1 & 1 & 2 & 3 \\
\hline 19 & 3 & 1 & 3 & 2 & 1 & 3 & 2 & 1 & 3 & 2 & 1 & 3 & 2 \\
\hline 20 & 3 & 1 & 3 & 2 & 2 & 1 & 3 & 2 & 1 & 3 & 2 & 1 & 3 \\
\hline 21 & 3 & 1 & 3 & 2 & 3 & 2 & 1 & 3 & 2 & 1 & 3 & 2 & 1 \\
\hline 22 & 3 & 2 & 1 & 3 & 1 & 3 & 2 & 2 & 1 & 3 & 3 & 2 & 1 \\
\hline 23 & 3 & 2 & 1 & 3 & 2 & 1 & 3 & 3 & 2 & 1 & 1 & 3 & 2 \\
\hline 24 & 3 & 2 & 1 & 3 & 3 & 2 & 1 & 1 & 3 & 2 & 2 & 1 & 3 \\
\hline 25 & 3 & 3 & 2 & 1 & 1 & 3 & 2 & 3 & 2 & 1 & 2 & 1 & 3 \\
\hline 26 & 3 & 3 & 2 & 1 & 2 & 1 & 3 & 1 & 3 & 2 & 3 & 2 & 1 \\
\hline 27 & 3 & 3 & 2 & 1 & 3 & 2 & 1 & 2 & 1 & 3 & 1 & 3 & 2 \\
\hline
\end{tabular}

Orthogonal array gives more reliable estimates of factor effects with less number of experiments, when compared to the traditional methods, such as one factor at a time experiments. In this process, six parameters at three levels each have been selected, so 36 experiments are required to be conducted in this case. But this number is reduced counting degrees of freedom, selecting L27 orthogonal array, which is possible array (suggested by Taguchi) which meets the requirement of this study as shown in tale. The experiments were conducted as per experimental layout shown \& the warpage in the part is measured \& noted for all set of parameters.

The $\mathrm{S} / \mathrm{N}$ ratio is the ratio of the mean (signal) to the standard deviation (noise). These $\mathrm{S} / \mathrm{N}$ ratios, derived from the quadratic loss function, are expressed on a decibel $(\mathrm{dB})$ scale. The formula used to compute the $\mathrm{S} / \mathrm{N}$ ratio depends on the objective function. Generally, three standard $\mathrm{S} / \mathrm{N}$ equations are widely used to classify the objective function as: 'larger the better', 'smaller the better', or 'nominal the best'. However, regardless of the type of performance characteristic, a smaller the better is always desirable.

Phase I : Matrix Experiment Details

Since warpage values are the response of our study, it can be suitably modified into corresponding $\mathrm{S} / \mathrm{N}$ ratios for incorporation into matrix experiment.

Warpage - Smaller-the-better

$\mathrm{S} / \mathrm{N}$ ration is measured through the MINITAB software \& the results are noted in the table 3

With the help of these values in MINITAB software main effect plot (Fig. 2) for all the parameters are plotted which gives us the set of optimized parameters that used for further experiments. Refer table 4 . 
Optimization of plastic moulding by reducing warpage with the Application of Taguchi optimization..

\section{Phase II}

Warpage is mainly depends on the process parameters, the part \& mold design. In Phase I in the experiments optimized process parameters were set \& experiments carried out on existing part (fig 3). Now to give the more stability to mass production \& make it smooth process flow part design modified. In this modification ribs were added to the lids at the point where warpage was more. With reference from previous research literatures \& on the basis of the experience ribs location \& thickness is provided. Generally Rib thickness given to be $1 / 2$ of the adjoining wall thickness. (Fig. 4)

Table 3 S/N ratio Calculation for warpage

\begin{tabular}{|c|c|c|c|c|c|c|c|}
\hline $\begin{array}{l}\text { Experi-ment } \\
\text { No. }\end{array}$ & $\begin{array}{l}\text { Melting } \\
\text { Temp. } \\
\text { (A) }\end{array}$ & $\begin{array}{l}\text { Injection } \\
\text { Pressure } \\
\text { (B) }\end{array}$ & $\begin{array}{l}\text { Packing } \\
\text { Pressure } \\
\text { (C) }\end{array}$ & $\begin{array}{l}\text { Packing Time } \\
\text { (D) }\end{array}$ & $\begin{array}{l}\text { Cooling Time } \\
\text { (E) }\end{array}$ & $\begin{array}{l}\text { Injection Speed } \\
\text { (F) }\end{array}$ & $\begin{array}{l}\mathrm{S} / \mathrm{N}(\mathrm{db}) \text { for } \\
\text { warpage }\end{array}$ \\
\hline 1 & 280 & 40 & 70 & 5 & 20 & 25 & -11.6158 \\
\hline 2 & 280 & 40 & 70 & 5 & 25 & 30 & -10.0567 \\
\hline 3 & 280 & 40 & 70 & 5 & 30 & 35 & -11.7721 \\
\hline 4 & 280 & 50 & 80 & 10 & 20 & 25 & -8.685 \\
\hline 5 & 280 & 50 & 80 & 10 & 25 & 30 & -7.5498 \\
\hline 6 & 280 & 50 & 80 & 10 & 30 & 35 & -6.5676 \\
\hline 7 & 280 & 60 & 90 & 15 & 20 & 25 & -9.36 \\
\hline 8 & 280 & 60 & 90 & 15 & 25 & 30 & -8.9525 \\
\hline 9 & 280 & 60 & 90 & 15 & 30 & 35 & -1.713 \\
\hline 10 & 290 & 40 & 80 & 15 & 20 & 30 & -8.7487 \\
\hline 11 & 290 & 40 & 80 & 15 & 25 & 35 & -7.6042 \\
\hline 12 & 290 & 40 & 80 & 15 & 30 & 25 & -8.158 \\
\hline 13 & 290 & 50 & 90 & 5 & 20 & 30 & -5.0716 \\
\hline 14 & 290 & 50 & 90 & 5 & 25 & 35 & -6.3821 \\
\hline 15 & 290 & 50 & 90 & 5 & 30 & 25 & -4.1257 \\
\hline 16 & 290 & 60 & 70 & 10 & 20 & 30 & -7.1967 \\
\hline 17 & 290 & 60 & 70 & 10 & 25 & 35 & -7.0436 \\
\hline 18 & 290 & 60 & 70 & 10 & 30 & 25 & -6.789 \\
\hline 19 & 300 & 40 & 90 & 10 & 20 & 35 & -7.9309 \\
\hline 20 & 300 & 40 & 90 & 10 & 25 & 25 & -5.9771 \\
\hline 21 & 300 & 40 & 90 & 10 & 30 & 30 & -1.0616 \\
\hline 22 & 300 & 50 & 70 & 15 & 20 & 35 & -9.0602 \\
\hline 23 & 300 & 50 & 70 & 15 & 25 & 25 & -5.747 \\
\hline 24 & 300 & 50 & 70 & 15 & 30 & 30 & -3.5218 \\
\hline 25 & 300 & 60 & 80 & 5 & 20 & 35 & -0.3823 \\
\hline 26 & 300 & 60 & 80 & 5 & 25 & 25 & -1.3414 \\
\hline 27 & 300 & 60 & 80 & 5 & 30 & 30 & -1.289 \\
\hline
\end{tabular}

\section{Main Effects Plot for SN ratios}

Data Means

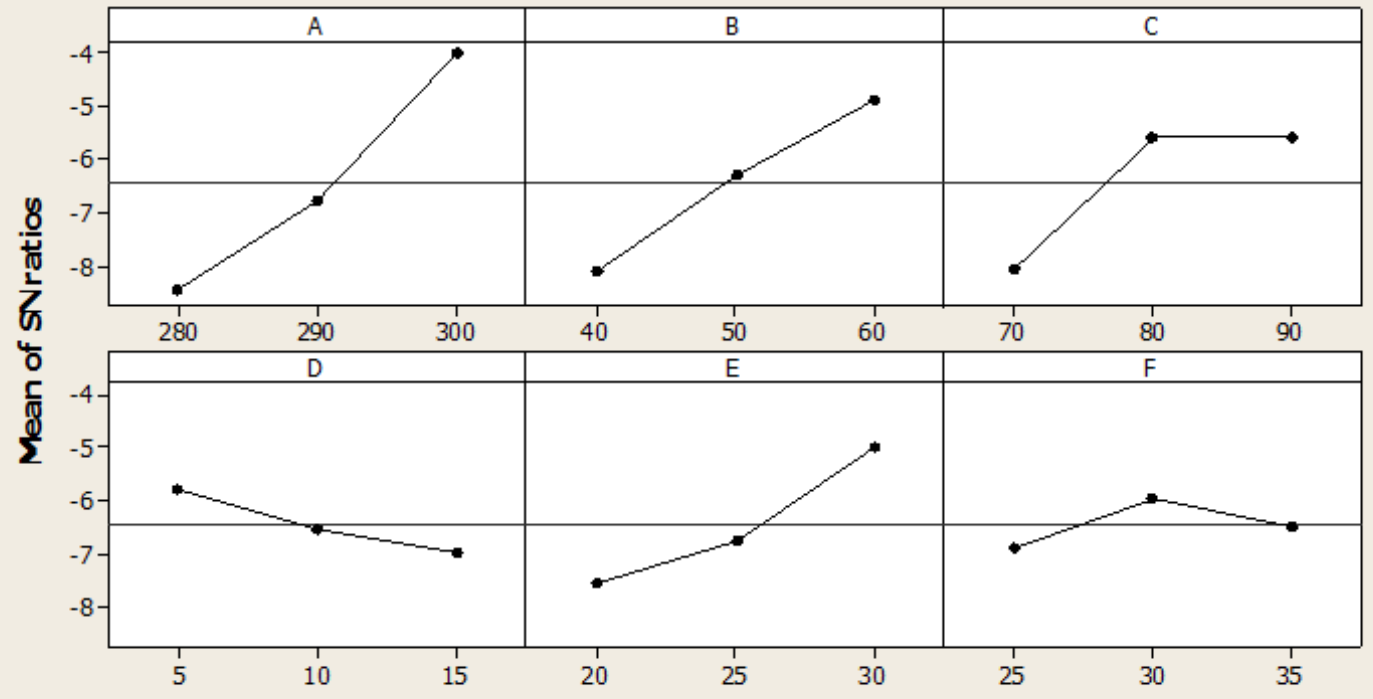

Signal-to-noise: Smaller is better

Fig. 2 Main Effects Plot of SN ratios for Warpage 
Optimization of plastic moulding by reducing warpage with the Application of Taguchi optimization..

Table 4 Optimized process parameters

\begin{tabular}{|l|l|l|l|l|l|l|l|}
\hline $\begin{array}{l}\text { Sr. } \\
\text { No. }\end{array}$ & Levels & \multicolumn{6}{|l|}{ Process Parameters } \\
\cline { 3 - 8 } & $\begin{array}{l}\text { Melting } \\
\text { Temp. }\left({ }^{\circ} \mathrm{C}\right) \\
(\mathrm{A})\end{array}$ & $\begin{array}{l}\text { Injection } \\
\text { Pressure(bar) } \\
(\mathrm{B})\end{array}$ & $\begin{array}{l}\text { Packing } \\
\text { Pressure(bar) } \\
(\mathrm{C})\end{array}$ & $\begin{array}{l}\text { Packing } \\
\text { Time(Sec) } \\
(\mathrm{D})\end{array}$ & $\begin{array}{l}\text { Cooling } \\
\text { Time(Sec) } \\
(\mathrm{E})\end{array}$ & $\begin{array}{l}\text { Injection } \\
\text { Speed(mm/s) } \\
(\mathrm{F})\end{array}$ \\
\hline 2 & $\begin{array}{l}\text { Optimum levels } \\
\text { for warpage }\end{array}$ & 300 & 60 & 80 & 5 & 30 & 30 \\
\hline
\end{tabular}

\section{Results and discussion}

For the warpage analysis purpose the modified drawing was analyzed in the Solid Edge Plastic Analysis software. Optimized process parameters obtained from the $\mathrm{S} / \mathrm{N}$ ratio analysis were given as an input \& the final result for the warpage were checked for overall part warpage $\&$ the warpage in the X-direction.

It was observed that added ribs provided more rigidity to the part. Ribs help to hold the part at the desired position \& restricts it from any deformation either outer or inner side. As ribs are less than half of the thickness of the adjoining wall thickness, it gets cooled rapidly compared to the wall. Due to this, ribs hold the walls of the part \& avoid the chances of deformation and hence warpage. Overall warpage for the lid without the rib with optimized parameters was $7.4 \mathrm{~mm} \&$ for the modified lids with ribs, overall warpage was 5.9 with same parameters. It means the total warpage in the lid is improved by around $22 \%$. Warpage in the X-direction for the lid without rib was $2.4 \mathrm{~mm} \&$ for the lid with the rib warpage was $1.5 \mathrm{~mm}$. it means it is improved by $37 \%$.

Also, stress distribution in the lid with ribs improved by $28 \%$ which gives additional strength to the part. Combination of optimal process parameters provided the smoothness to the flow but to make it more stable process \& more smooth flow during mass production part design modifications has helped. Added ribs confirm the part dimensions \& therefore reduce any deformation possibilities even during slight changes in the atmospheric conditions.

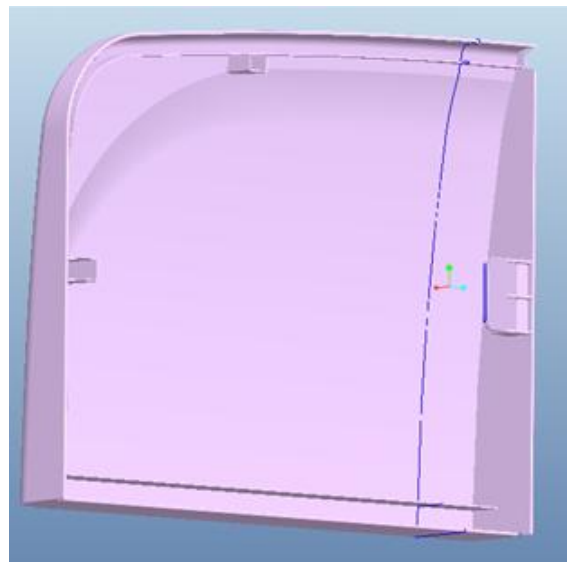

Fig 3 : Wash lid Without rib

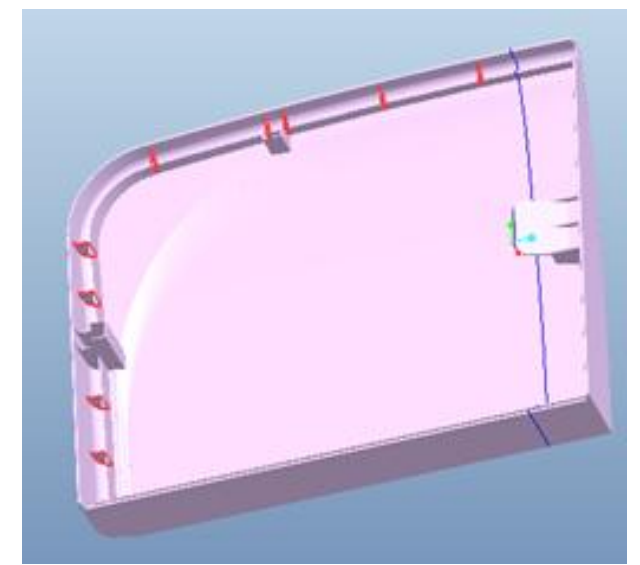

Fig 4: Wash lid with ribs

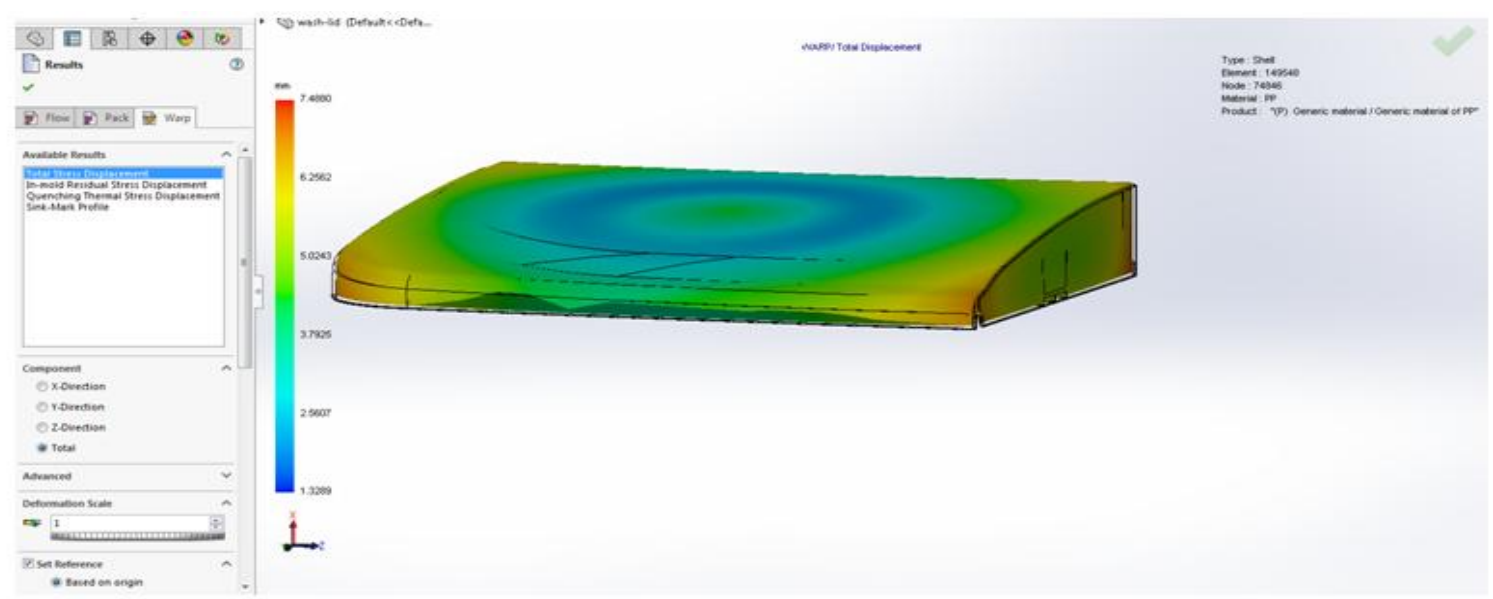

Fig 5: Warpage analysis (Total)-Without Ribs [Maximum warpage 7.4mm] 


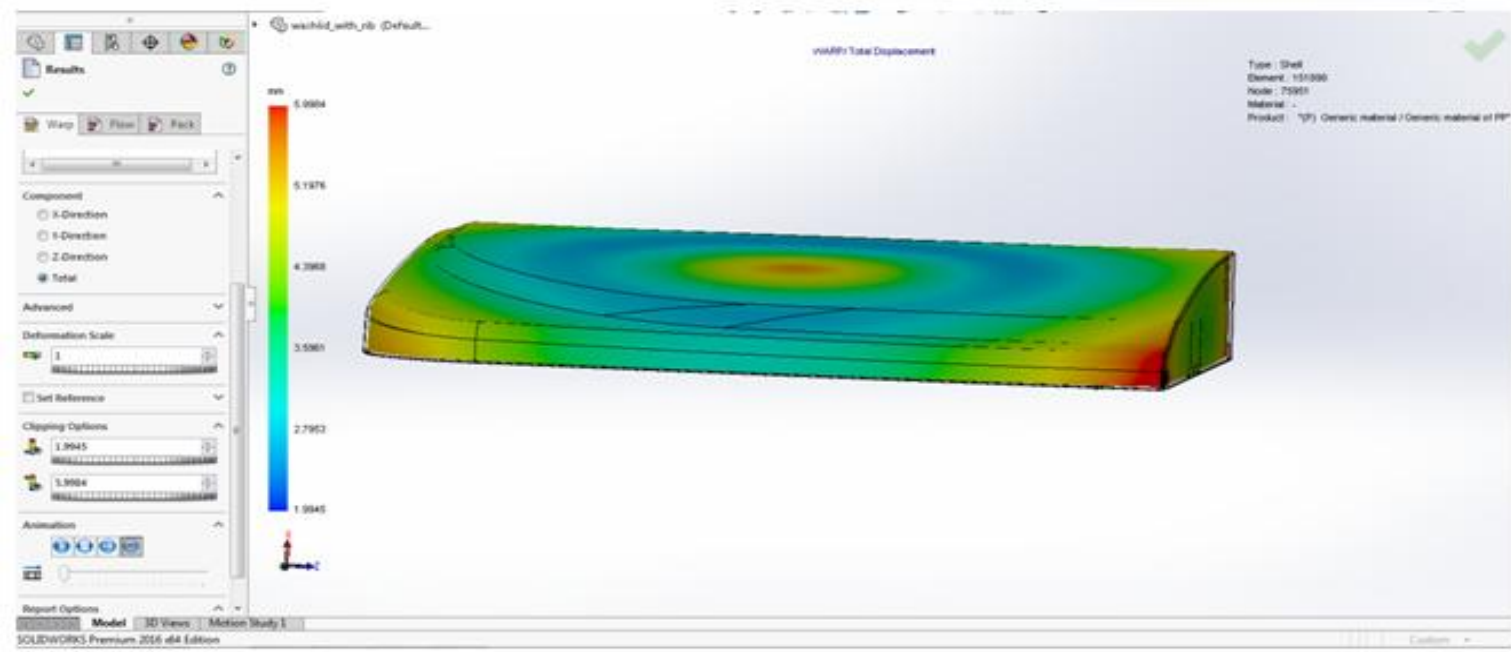

Fig 6 Warpage analysis (Total)-With Ribs [Maximum warpage 5.9mm]

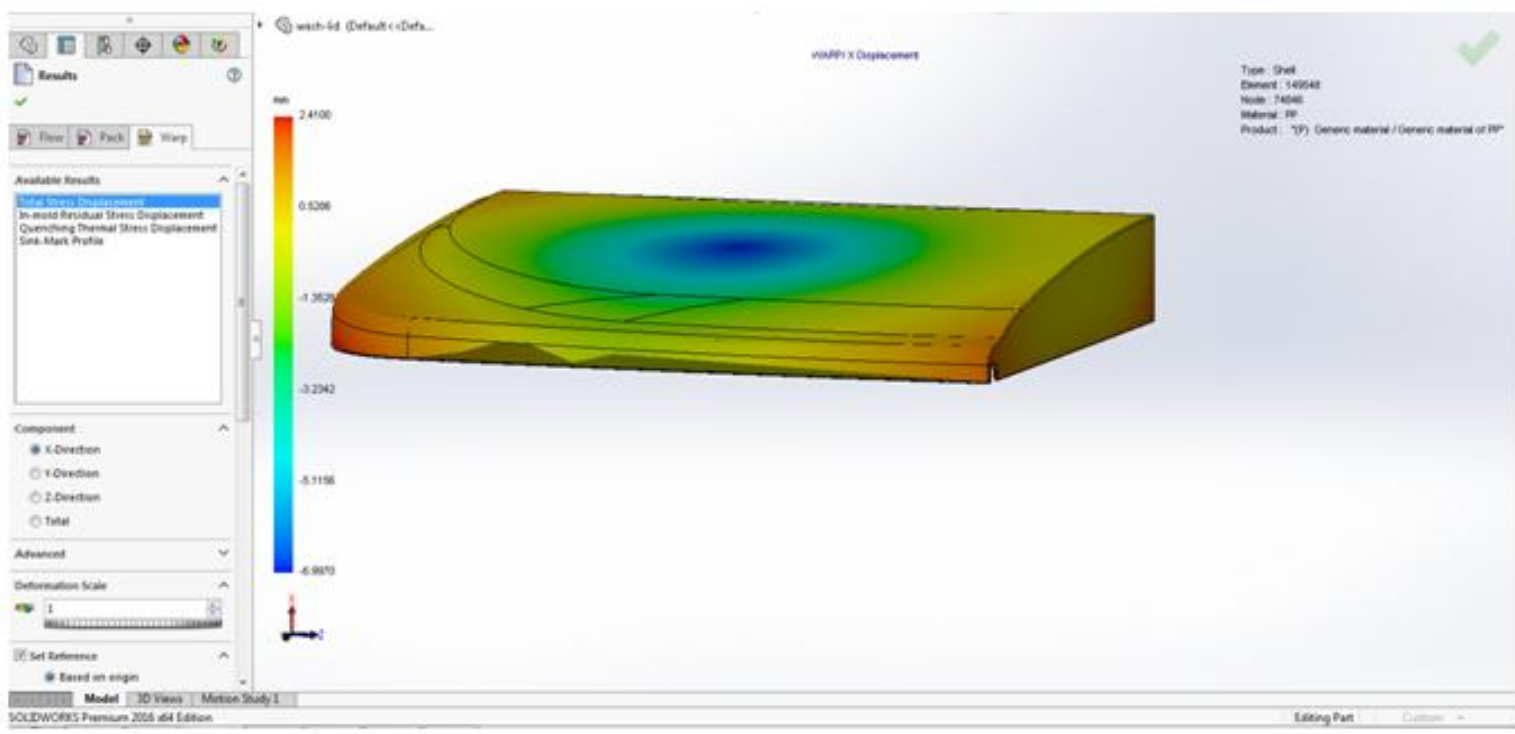

Fig 7 Warpage analysis (X-Direction)-Without Ribs [Maximum warpage 2.4mm]

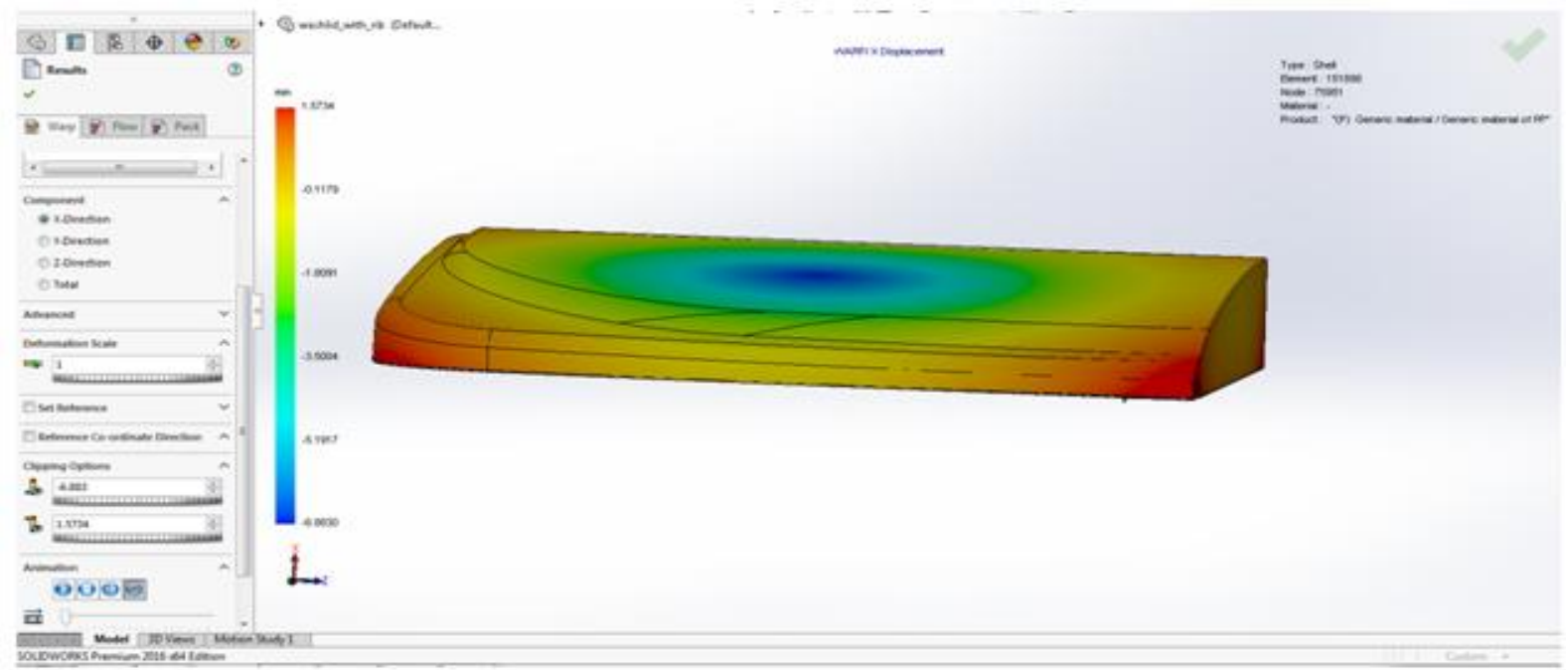

Fig 8 Warpage analysis (X-Direction)-With Ribs [Maximum warpage $1.5 \mathrm{~mm}$ ] 


\section{Conclusion}

The Study was successfully investigated $\&$ the results were in line with the expectations.

Taguchi optimization method was used to achieve the optimized set of parameters.

By applying the $\mathrm{S} / \mathrm{N}$ ratio results, it is observed that the optimum process conditions of melt temperature of $300^{\circ}$ $\mathrm{C}$, injection pressure of $60 \mathrm{bar}$, packing pressure of $80 \mathrm{bar}$, packing time of $5 \mathrm{~s}$, cooling time of 30s and injection speed of $30 \mathrm{~mm} / \mathrm{s}$ yield minimum warpage.

The minimum warpage is calculated as $1.5 \mathrm{~mm}$, which is smaller than $2.4 \mathrm{~mm}$ in the analysis results. It can be inferred that the warpage is improved by about $37.28 \%$.

Further, the design modifications made by adding ribs to the wash lid provided more stability, sustainability \& facilitated smooth flow for mass production of the component.

\section{References}

[1]. Hasan Oktem, Tuncay Erzurumlu, Ibrahim Uzma. Application of Taguchi optimization technique in determining plastic injection molding process parameters for a thin-shell part; Material \& Design, 28, Elsevier, 2007,1271-1278

[2]. Eghbal Hakimian, Abu Bakar Sulong. Analysis of warpage and shrinkage properties of injection-molded micro gears polymer composites using numerical simulations assisted by the Taguchi method; Material \& Design, 42, Elsevier; 2012, $62-71$

[3]. Nik Mizamzul Mehata, Shahrul Kamaruddin. Optimization of mechanical properties of recycled plastic products via optimal processing parameters using the Taguchi method; Journal of Materials Processing Technology 211, Elsevier, 2011, 1989-1994

[4]. Ming-Chih Huang, Ching-Chih Tai. The effective factors in the warpage problem of an injection-molded part with a thin shell feature; Journal of Materials Processing Technology, 110, Elsevier, 2001, 1-9

[5]. E. Bociga, T. Jaruga, K. Lubczyñska, A. Gnatowski. Warpage of injection moulded parts as the result of mould temperature difference; Archives of material Science and Engineering, 44, 2010, 28-34

[6]. S.Selvaraj, P.Venkataramaiah Measurement of warpage of injection moulded Plastic components using image processing; International journal of innovative research in science, 2, IJIRSET, ISSN 2319-8753, 2013

[7]. Sen-Yeu Yang, Shin-Chang Jiang, and Wen-Shu Lu. Ribbed Package Geometry for Reducing Thermal Warpage and Wire Sweep During PBGA Encapsulation; Transactions on component and packaging technologies, IEEE, 23, 2000

[8]. Mr. Anandrao B. Humbe1, Dr. M.S. Kadam2. Optimization of critical processing parameters for enhanced productivity \& reduced time for development; International journal of mechanical engineering and technology, IJMET, ISSN 0976-6340, 2013, 223-226

[9]. S. Kamaruddin, Zahid A. Khan and S. H. Foong. Application of Taguchi Method in the Optimization of Injection Moulding Parameters for Manufacturing Products from Plastic Blend, International journal of Engineering and Technology, IACSIT, 2, ISSN $1793-8236,2010$

[10]. S.M. Nasir, K.A. Ismail, Z. Shayfull, M.A. Md. Derus Warpage Improvement of Thick Component Using Taguchi Optimization Method for Single and Double Gates in Injection Molding Process, Australian journal of basic and applied sciences, 7(5), ISSN $1991-8178,2013,205-212$

[11]. A.M. Gwebu1*, L. Nyanga ${ }^{2}$, S.T. Nyadongo ${ }^{3}$, A.F. Van der Merwe4, S Mhlanga5. Effect of mould temperature on the filling behavior of molten resin in plastic injection moulding of HDPE, SAIIE 26, 2014 